\title{
The Inhibitive Effect of Carbon Containing Corrosion Products Inside Corrosion Pits on the Repassivation of Carbon Steels
}

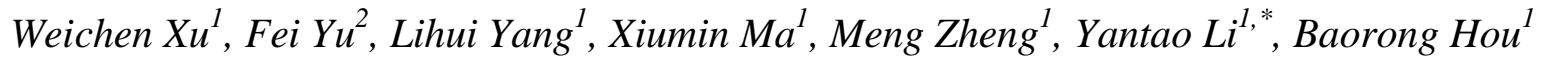 \\ ${ }^{1}$ Institute of Oceanology, Chinese Academy of Sciences, Qingdao 266071, China \\ ${ }^{2}$ Medical College, Qingdao University, Qingdao 266021, China \\ *E-mail: ytli@qdio.ac.cn
}

doi: $10.20964 / 2016.06 .78$

Received: 14 March 2016 / Accepted: 15 April 2016 / Published: 4 May 2016

The effect of carbon containing corrosion products within corrosion pits on the repassivation of pits has been studied on $20 \#$ and $45 \#$ carbon steels in sodium chloride and sodium hydroxide / nitrate / nitrite solutions. Anodic polarisation tests have been carried out in an attempt to cause pitting corrosion and then measure the repassivation potential. The presence of corrosion products within pits has been demonstrated via EDX. Pits in $0.1 \mathrm{M} \mathrm{NaNO}_{2}$ solutions with different concentrations of $\mathrm{NaCl}$ (20 mM, $40 \mathrm{mM}, 0.1 \mathrm{M}$ and $0.2 \mathrm{M}$ ) have been found to repassivate at different potentials. The repassivation potential of $45 \#$ carbon steel is lower than that of $20 \#$ when carbon containing corrosion products are detected within corrosion pits, but the difference is negligible when the products are not detected. The presence and absence of carbon containing corrosion products is found to depend on the concentration of chloride. The difference on the repassivation potentials has been ascribed to the inhibitive effect of corrosion products on metal ion diffusion, which may maintain aggressive solution within pits and inhibit repassivation at a low dissolution rate. It has also been found that pits cannot repassivate in $\mathrm{NaOH}$ and $\mathrm{NaCl}$ solutions, while pitting corrosion cannot take place in $\mathrm{NaNO}_{3}$ and $\mathrm{NaCl}$ solutions.

Keywords: pitting corrosion, repassivation, corrosion products, carbon

\section{FULL TEXT}

(C) 2016 The Authors. Published by ESG (www.electrochemsci.org). This article is an open access article distributed under the terms and conditions of the Creative Commons Attribution license (http://creativecommons.org/licenses/by/4.0/). 